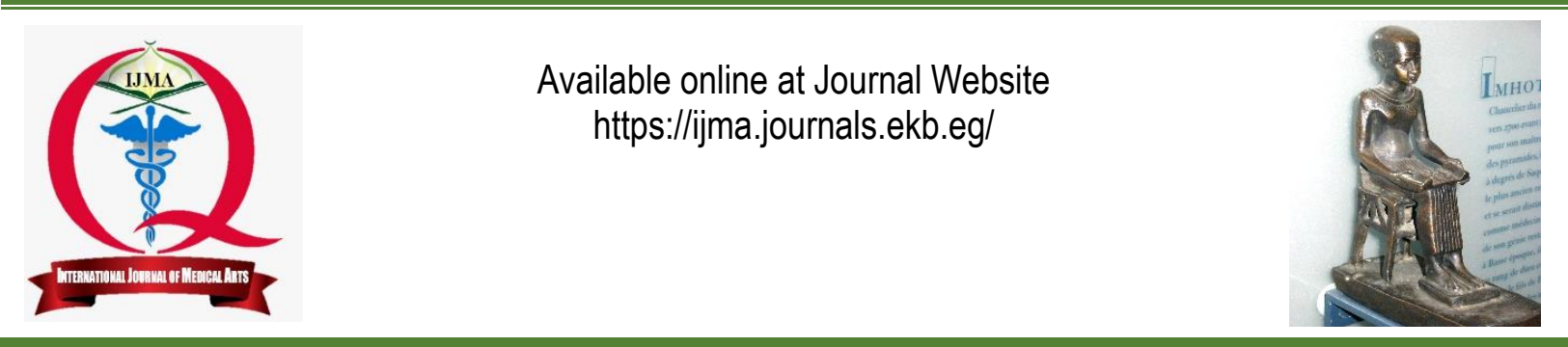

Original article

\title{
Correlation between Vitamin-D Level and Pulmonary Function Tests in Children with Bronchial Asthma
}

Magdy Sakr ${ }^{a}$, Mohamed Elsamnody ${ }^{a}$, Atef Wahdan Elrifai ${ }^{b}$, Hesham Samir Abd-Al-Samee ${ }^{c}$, Ahmed Arafa Saad $^{a}$ Department of Pediatrics, Damietta Faculty of Medicine, Al-Azhar University, Egypt[a]

Department of Chest Diseases, Damietta Faculty of Medicine, Al-Azhar University, Egypt [b]

Department of Clinical Pathology, Damietta Faculty of Medicine, Al-Azhar University, Egypt $[\mathrm{c}]$

Corresponding author: Ahmed Arafa Saad

Email: drmohamedataya@gmail.com

Received at: September 3, 2019; Revised at: February 3, 2020; Accepted at: February 3, 2020; Available online at: February 3, 2020 DOI: 10.21608/ijma.2020.14621.1018

\section{ABSTRACT}

Background: Bronchial asthma Affecting 1-18\% of children in different countries, it widely distributed chronic respiratory disease. vitamin-D increase calcium absorption from the gastrointestinal tract, determines bone health and regulates neuromuscular function. In addition, vitamin-D is a potent immune system regulator, and it has a potential role in various allergic diseases.

Aim of the work: To estimate the association between asthma and Vitamin-D in pediatrics.

Patients and methods: The present work is a case control study included 150 [100 asthmatic children and 50 healthy control] children aged between 5 and 12 years. Serum 25- hydroxy vitamin-D levels were evaluated and compared between two groups. Association between vitamin-D and pulmonary function was studied in asthmatic children.

Results: Cases had significantly lower values of FEV1\%, FEV1/FVC ratio and vitamin-D levels when compared to controls $[53.20 \pm 6.27,68.64 \pm 4.42,24.44 \pm 20.92$ vs $126.44 \pm 10.15,107.20 \pm 5.05$ and $84.25 \pm 41.79$ successively]. In addition, vitamin-D was positively and significantly correlated with pulmonary function tests [FEV1\% and FEV1/FVC ratio].

Conclusion: Children with bronchial asthma suffered from marked reduction of vitamin-D which correlated with asthma severity.

Keywords: Bronchial Asthma; Children; Lung function; Vitamin-D; Correlation.

This is an open access article under the Creative Commons license [CC BY] [https://creativecommons.org/licenses/by/2.0/]

Please cite this article as Sakr M, Elsamnody M, Elrifai AW, Abd-Al-Samee HS, Saad AA. Correlation between Vitamin-D Level and Pulmonary Function Tests in Children with Bronchial Asthma. IJMA 2020; 2[1]: 308-312. 


\section{INTRODUCTION}

Bronchial Asthma is a heterogeneous condition with hallmark chronic airway inflammation with variable expiratory airflow limitation; clinically, there was wheezy chest, shortness of breath and cough; these symptoms vary from time to time in frequency and intensity [1].

Increased prevalence of bronchial asthma may be explained by different etiologies; i.e., environmental [air pollution, different allergens, weather changes], lifestyle and dietary factors [2].

Hallmark of bronchial asthma is airway obstruction due to interaction between inflammatory mediators, immune cells and impaired immunogenic tolerance [3].

Vitamin-D play important role in neuromuscular function, hormone secretion [insulin] and calcium absorption from gastrointestinal tract [GIT]; in immune system, vitamin-D is a potent regulator and proposed to play a major role in different allergic diseases [4].

However, the existence of a link between vitamin-D and bronchial asthma or allergy need further investigation [5].

\section{AIM OF THE WORK}

To estimate the association between asthma and Vitamin-D in pediatrics.

\section{PATIENTS AND METHODS}

Case control study included 150 children in number aged between 5 and 12 years old at Pediatric department [outpatient and inpatient] of New Damietta faculty of medicine, Al-Azhar University; in two working days per week from $1 / 1 / 2018$ to $31 / 12 / 2018$.

One Hundred of them were suffering from bronchial asthma and 50 were healthy; age and sex matched children taken as a control group. Children with the following criteria were included in the present work: 1] Children known to be asthmatics according to GINA [Global Initiative for Asthma Guidelines] 2017. On the other side, children with one or more of the following were excluded from the study: 1] Children having chest diseases rather than asthma; 2] rickets; 3] apparent congenital anomalies; 4] Chronic liver, kidney, endocrine diseases; 5] on vitamin-D supplementation for the past one year; 6] medication that affect vitamin-D as phenobarbital, carbamazepine, phenytoin, clotrimazole, ketoconazole, rifampin and isoniazid.

Collected data included child's demographics, anthropometric measurements and residence. In addition, details of sun exposure during the last month [duration of exposure per day and time of exposure] were measurement and documented [6]

$3 \mathrm{ml}$ of venous blood were collected in a plain tube under complete aseptic technique for each participant. Each sample was centrifuged and serum was separated and stored at $-20^{\circ} \mathrm{C}$ till analysis. The sample was analyzed for the following tests: serum vitamin-D levels, complete blood count [CBC] for eosinophilia as well as total and differential WBCs count.

25-Hydroxy Vitamin-D values were measured by ELISA kit [KAP 1971/F1, Dia source immunoassays S.A] and values expressed in $\mathrm{ng} / \mathrm{ml}$. Serum level was classified as the following: deficient $[<20 \mathrm{ng} / \mathrm{mL}]$, insufficient $[20-30 \mathrm{ng} / \mathrm{mL}]$ and sufficient $[>30 \mathrm{ng} / \mathrm{mL}]^{[7]}$.

Pulmonary function tests were studied according to guidelines by the American Thoracic Society 2007 by using diagnostic spirometry [ZAN Mebgerate $\mathrm{GmbH}$ with abuilt-in computer] manufactured by nnd Medizintechnik AG, 8005 Zurich, Switzerland] ${ }^{[8]}$.

Statistical analysis: A pre-formed excel sheet was used in collection of data according to standard prepared questionnaires. Then, data were transferred to statistical package for social science for analysis. The use version of SPSS was 22 [SPSS, Inc. Chicago, IL, USA]. Data were presented in the form of mean \pm standard deviation [SD] for numerical normally distributed data and expressed in the form of numbers and percentage for qualitative variables. Student t-test, and Chisquare were used for comparison between groups. The correlations were analyzed by Pearson correlation coefficients. A $p$-value $<0.05$ was considered significant.

\section{RESULTS}

100 asthmatic children and 50 healthy controls were included in the present work, and there was no significant difference between cases and 
Sakr M, et al.

controls regarding patient age or sex [Table 1].

In addition, they were comparable as regard to their weight, height and body mass index [BMI]. On the other side, cases had significantly lower values of $\mathrm{FEV} 1 \%$, FEV1/FVC ratio and vitamin-D levels when compared to controls [53.20 $26.27,68.64 \pm$ $4.42,24.44 \pm 20.92$ vs $126.44 \pm 10.15,107.20 \pm 5.05$ and $84.25 \pm 41.79$ successively] [Table 2].

Furthermore, there was significant increase of asthma with deficient and insufficient vitamin-D levels $[45.0 \%, 38.0 \%$ vs $0.0 \%$ and $20.0 \%$ respectively] and vitamin-D children were sufficient in controlled groups [17.0\% vs $80.0 \%$ respectively] [Table 3].

Finally, there were a significant positive correlation between serum levels of vit. D, FEV1\% and FEV1/FVC ratio in asthmatic children [Table 4], as there was a significant reduction of pulmonary function tests [FEV1\% and FEV1/FVC ratio] in vitamin-D deficient children when compared to children with insufficient or sufficient vitamin-D levels and in children with insufficient vitamin-D when compared to those with sufficient vitamin-D [Table 5].

Table [1]: Comparison between cases and controls as regard to age and gender

\begin{tabular}{|l|l|c|c|c|c|}
\hline \multicolumn{2}{|c|}{ Variables } & Cases & Controls & Total & P value \\
\hline Age & $7.92 \pm 2.30$ & $8.62 \pm 2.35$ & $8.15 \pm 2.33$ & $>0.05[\mathrm{~ns}]$ \\
\hline \multirow{2}{*}{ Sex } & Male & $26[52.0 \%]$ & $24[48.0 \%]$ & $50[100.0 \%]$ & \multirow{2}{*}{$>0.05[\mathrm{~ns}]$} \\
\cline { 2 - 5 } & Female & $58[58.0 \%]$ & $42[42.0 \%]$ & $100[100.0 \%]$ & \\
\hline
\end{tabular}

ns: non-significant

Table [2]: Comparison between cases and controls as regard to anthropometrics, FEV1\%, and FEV1/FVC ratio and serum vitamin-D levels

\begin{tabular}{|l|c|c|c|}
\hline & $\begin{array}{c}\text { Cases } \\
{[\mathrm{n}=100]}\end{array}$ & $\begin{array}{c}\text { Controls } \\
{[\mathrm{n}=50]}\end{array}$ & $\begin{array}{c}\mathrm{P} \\
\text { value }\end{array}$ \\
\hline Weight [i $\mathrm{kg}]$ & $27.84 \pm 7.10$ & $29.86 \pm 7.80$ & 0.114 \\
\hline Height $[\mathrm{in} \mathrm{cm}]$ & $122.79 \pm 17.26$ & $127.52 \pm 16$ & 0.107 \\
\hline BMI $\left[\mathrm{Kg} / \mathrm{m}^{2}\right]$ & $18.41 \pm 1.97$ & $18.10 \pm 1.93$ & 0.359 \\
\hline FEV1\% & $53.20 \pm 6.27$ & $126.44 \pm 10.15$ & $<0.001^{*}$ \\
\hline FEV1/FVC ratio & $68.64 \pm 4.42$ & $107.20 \pm 5.05$ & $<0.001^{*}$ \\
\hline 25-hydroxy vitamin-D levels [ng/mL] & $24.44 \pm 20.92$ & $84.25 \pm 41.79$ & $<0.001^{*}$ \\
\hline
\end{tabular}

Table [3]: Comparison between study and control groups as regard to grouping of vitamin-D.

\begin{tabular}{|l|c|c|c|c|}
\hline & $\begin{array}{c}\text { Cases } \\
\mathrm{N}=100[\%]\end{array}$ & $\begin{array}{c}\text { Controls } \\
\mathrm{N}=50[\%]\end{array}$ & $\begin{array}{c}\text { Total } \\
\mathrm{N}=150[\%]\end{array}$ & \\
\hline Deficiency $[<20 \mathrm{ng} / \mathrm{mL}]$ & $45[45 \%]$ & $0[0 \%]$ & $45[30 \%]$ & \multirow{2}{*}{$<0.001^{*}$} \\
\cline { 1 - 4 } Insufficiency $[20-30 \mathrm{ng} / \mathrm{mL}]$ & $38[38 \%]$ & $10[20 \%]$ & $48[32 \%]$ & \\
\hline Sufficiency $[>30 \mathrm{ng} / \mathrm{mL}]$ & $17[17 \%]$ & $40[80 \%]$ & $57[38 \%]$ & \\
\hline
\end{tabular}

Table [4]: Correlation between serum levels of Vit. D and FEV1\% and FEV1/FVC ratio in asthmatic children.

\begin{tabular}{|c|c|c|c|c|c|c|}
\hline $\begin{array}{c}\text { Vit. D levels } \\
{[\mathrm{nmol} / /]}\end{array}$ & FEV1\% & r & $P$ & FEV1/FVC ratio & $r$ & $P$ \\
\hline Mean $\pm S D$ & Mean \pm SD & \multirow[b]{2}{*}{0.281} & \multirow{2}{*}{$<0.001^{*}$} & Mean \pm SD & \multirow{2}{*}{0.321} & \multirow{2}{*}{$0.001^{*}$} \\
\hline $24.44 \pm 20.92$ & $53.20 \pm 6.27$ & & & $68.64 \pm 4.42$ & & \\
\hline
\end{tabular}

Table [5]: Comparison between different vitamin-D groups regarding pulmonary function

\begin{tabular}{|l|c|c|c|c|}
\hline & Vitamin-D deficient [n=45] & Vitamin-D insufficient [n=38] & Vitamin-D sufficient [n=17] & $p$-value \\
\hline FEV1\% & $50.49 \pm 5.76$ & $54.87 \pm 5.56$ & $56.65 \pm 6.38$ & $<0.001^{*}$ \\
\hline FEV1/FVC\% & $66.84 \pm 4.35$ & $69.53 \pm 3.77$ & $70.35 \pm 4.71$ & $0.003^{*}$ \\
\hline
\end{tabular}

\section{DISCUSSION}

Bronchial Asthma in children is one of the commonest respiratory diseases all over the world. Vitamin-D, being fat-soluble vitamin and a steroid hormone plays a functional role to increase absorption of calcium and maintains bone health.
Reduced concentrations of vitamin-D play role in different cardiovascular disorders, development of inflammation \& infectious diseases, diminished physical functions, allergy and all-cause mortality [4, 9]. Relation between bronchial asthma and vitamin$D$ remains controversial. Thus, the present research aimed to estimate serum 25-hydroxy vitamin-D 
levels in children with asthma and investigate the role of vitamin-D in those children. Vitamin-D was significantly reduced in asthmatic children. In addition, $45 \%$ of the asthmatic children were vitamin-D deficient. One study from Thai reported that, $64 \%$ of children with bronchial asthma were vitamin-D deficient [10].

In the present work, sun exposure was significantly reduced in asthmatic patients. This could be attributed to more time spent indoor by asthmatic children because childhood bronchial asthma frequently leads to personal activity limitation and high school absence rate [11].

We could say that, in the present work, vitamin-D levels positively correlated with pulmonary function tests. The pathogenic role of vitamin-D could be explained in several ways: first, due to immune deficiency as it has been associated to other many immunological diseases such as Cron's disease, inflammatory bowel disease, diabetes mellitus, multiple sclerosis or rheumatoid arthritis [10, 11]. Second; vitamin-D had a modulatory role on the immune system; for example, it could promote sensitivity of steroids and down regulate the inflammation state by cytokine production or alternation in gene expression; the action which could affect airway directly. Third; vitamin-D receptors were found in the airway and vitamin-D deficiency could lead to failure in inflammatory state turning off, after acute inhalational insult, and upregulation of inflammatory mediators such as prostaglandin, leukotriene and macrophage activity $[12,13]$. Results of the present trial agree with previous studies, reported that, children with good pulmonary function tests [FEV1\%] had higher values of serum $25[\mathrm{OH}] \mathrm{D}[14,15]$. In addition, vitamin$D$ deficiency could be associated with irreversible loss of lung function due to airway remodeling with structural changes of airway walls caused by recurrent injury and repair processes [16]. Other studies could correlate asthma severity to reduced vitamin-D levels $[10,17,18]$. Thus, confirming its role in pathogenesis of bronchial asthma.

In conclusion, vitamin-D was significantly lower among asthmatic children when compared to healthy controls, and there was significant relationship between vitamin-D levels and pulmonary function tests. Thus, routine measurement of vitamin-D in asthmatic children is advocated. However, future studies were needed to examine the role of vitamin-D supplementation on the bronchial asthma in pediatrics.

\section{Financial and Conflict of interest disclosure}

Authors declare that there was no conflict of interest.

\section{REFERENCES}

1- Global initiative for asthma [GINA]. From the Global Strategy for Asthma Management and prevention http://www.ginasthma.org/. [accessed 18 December 2018].

2- Van der Werff SD, Diaz JR, Reyneveld R, Heymans MW, Ponce Campos M, Gorbea Bonet M, Polman K. Prediction of asthma by common risk factors: a follow up study in Cuban school children J Investing Allergol Clin Immunol. 2013: 23[6] :415-420. [PMID:24459818].

3- Holt PGM, Strickland DH. Interactions between innate and adaptive immunity in asthma pathogenesis; new perspectives from studies on acute exacerbations. J Allergy Clin Immunol. 2010; 125: 936-972. [DOI: 10.1016/j.jaci.2010.02.011].

4- Brown SD, Calvert HH, Fitzpatrick AM. Vitamin D and asthma. Dermato-Endocrinology 2012; 4[2]: 137-145. [DOI: 10.4161/derm.20434].

5- Shebl ER, Shehata SM, Elgabry M, Ali SA, Elsaid HH. Vitamin D and phenotypes of bronchial asthma. Egy J Chest Dis Tuberculosis 2013; 62[2]: 201-205. [DOI: 10.1016/j.ejcdt.2013.06.006].

6- Joint FAO/WHO Expert Consultation. Vitamin and mineral requirements in human nutrition http:// hyqlibdoc.who.int/publications/2004/9241546123. pdf [accessed 20 June 2019].

7- Holick MF, Binkley NC, Bischoff-Ferrari HA, Gordon CM, Hanley DA, Heaney RP, et al. Evaluation, treatment, and prevention of vitamin $\mathrm{D}$ deficiency: an Endocrine Society clinical practice guideline. J Clin Endocrinol Metab. 2011; 96[7]: 1911-1930. [DOI: 10.1210/jc.2011-0385].

8- American Thoracic Society. Standardization of Spirometry 1994. Am. J. Respir Crit Care Med. 1995; 152[3]:1107-36. [DOI: 10.1164/ajrccm. 152.3. 7663792] 
9- Bener A, Ehlayel MS, Tulic MK, Hamid Q. Vitamin $D$ deficiency as a strong predictor of asthma in children. Int Arch Allergy Immunol. 2012; 157; 168175. [DOI: 10.1159/000323941].

10-Krobtrakulchai W, Praikanahok J, Visitsunthorn $\mathrm{N}$, Vichyanond P, Manonukul K, Pratumvinit B, et al. The effect of vitamin $D$ status on pediatric asthma at a university hospital, Thailand. Allergy Asthma Immunol Res. 2013; 5[5]: 289-294. [DOI: 10.4168/aair.2013.5.5.289.].

11- Global initiative for asthma [GINA], From the Global Strategy for Asthma Management and prevention 2014 and National Institute of health $[\mathrm{NIH}]$. Available at http://www.ginasthma.org/local/ uploads/files/GINA_Report_2014.pdf

12- Prieti B, Treiber G, Pieber TR, Amrein K. Vitamin $D$ and Immune function. Nutrients 2013; 5: $2502-$ 2521. [DOI: 10.3390/nu5072502].

13- Huang HM, Porpodis K, Zarogoulidis P, Domvrim $K$, Giouleka P, Papaiwannou A, et al. Vitamin D in asthma and future perspectives. Drug Des Devel Ther. 2013; 7: 1003-1013. [DOI: 10.2147/ DDDT. S50599].
14- Gupta A, Sjoukes A, Richards D, Banya W, Hawrylowicz C, Bush A, Saglani S. Relationship between serum vitamin $D$ disease severity and airway remodeling in children with asthma. Am J Respir Crit Care Med. 2011; 184: 1342-1349. [DOI: 10.1164/rccm.201107-12390C].

15- Chinellato I, Piazza M, Sandri M, Peroni D, Paicentini G, Boner Al. Vitamin D serum levels and markers of asthma control in Italian children. J Pediatr 2011; 158: 437-441. [DOI: 10.1016/j.jpeds. 2010.08.043].

16- Berraies A, Hamzaoui A. Link Between vitamin D and airway remodeling. J asthma allergy 2014: 7: 23 - 30. [DOI: 10.2147/JAA.S46944].

17- Devereux G, Wilson A, Avenell A, McNeill G, Fraser WD. A case control study of vitamin $D$ status and asthma in adults. Allergy 2010; 65: 666667. [DOI: 10.1111/j.1398-9995.2009. 02220.x].

18. Ozturk Thomas G, Tutar E, Tokuc G, Oktem S. 25-hydroxy Vitamin D Levels in Pediatric Asthma Patients and its Link with Asthma Severity. Cureus 2019; 11[3]: e4302. [DOI: 10.7759/cureus.4302]. 